\title{
Localization of vascular endothelial growth factor and its receptor, flt, in human placenta and decidua by immunohistochemistry
}

\author{
J. C. Cooper, A. M. Sharkey, J. McLaren, D. S. Charnock-Jones and \\ S. K. Smith \\ Reproductive Molecular Research Group, Department of Obstetrics and Gynaecology, \\ University of Cambridge, Rosie Maternity Hospital, Robinson Way, CB2 2SW, UK
}

\begin{abstract}
Vascular endothelial growth factor is a secreted angiogenic growth factor the mRNA of which is present in the placenta. The mRNA encoding the vascular endothelial growth factor receptor, flt, has also been demonstrated in placenta, with trophoblast appearing to be a novel site of flt expression. We investigated the expression of both vascular endothelial growth factor and flt-like immunoreactivity in first trimester and term placentae. In the first trimester, vascular endothelial growth factor immunoreactivity was localized to placental macrophages (Hofbauer cells), and in decidua, to glandular epithelium and maternal macrophages. In the term placenta, vascular endothelial growth factor immunoreactivity was present in extravillous trophoblast and in extracellular material. Flt immunoreactivity was demonstrated on extravillous trophoblast in first trimester and term, and on Hofbauer cells within placental villi. This complex pattern of both vascular endothelial growth factor and flt-like immunoreactivity suggests that vascular endothelial growth factor may be involved not only in the regulation of placental angiogenesis, but also in trophoblast invasion.
\end{abstract}

\section{Introduction}

The establishment of pregnancy depends upon the mechanisms of formation of close contacts between fetal and maternal tissues. The starting point is the attachment of the blastocyst to the uterine wall, and the invasion of the decidua by trophoblast derived from embryonic trophectoderm. While the trophoblast is penetrating, the maternal arteries continue to elongate until well into the first trimester. Extensive angiogenesis occurs both in the fetal villi and in the maternal decidua, to establish the vascular structures required for exchange (Findlay, 1986). This involves proliferation, migration and maturation of maternal and fetal endothelial cells (Klagsbrun and D'Amore, 1991).

Vascular endothelial growth factor (VEGF), a secreted angiogenic growth factor, has widespread tissue distribution and is implicated in the development of both pathological and physiological angiogenesis (Ferrara and Henzel, 1989; Ferrara, 1993). In addition to its mitogenic properties, VEGF induces proteinase expression (Mignatti et al., 1989; Unemori et al., 1992), stimulates monocyte and endothelial cell chemotaxis (Clauss et al., 1990; Koch et al., 1994) and may act to maintain the vascular endothelium (Jakeman et al., 1992). It is a homodimeric heparin-binding glycoprotein with five different isoforms arising from alternative splicing of its mRNA. Four of these isoforms $\left(\mathrm{VEGF}_{121}, \mathrm{VEGF}_{145}, \mathrm{VEGF}_{165}\right.$ and $\left.\mathrm{VEGF}_{189}\right)$ are present in pregnant and nonpregnant uteri (Charnock-Jones et al., 1993; Sharkey et al., 1993), and the fifth $\left(\mathrm{VEGF}_{206}\right)$ has been demonstrated only in a fetal liver cDNA library (Houck

Revised manuscript received 14 March 1995 et al., 1992). All splice variants are secreted proteins, but $\mathrm{VEGF}_{121}$ and $\mathrm{VEGF}_{165}$ are soluble, whereas $\mathrm{VEGF}_{189}, \mathrm{VEGF}_{206}$ and probably VEGF $_{145}$ are bound to heparin-containing proteoglycans on the cell surface, basement membrane or extracellular matrix (Houck et al., 1992; Charnock-Jones et al., 1993). Little is known about their functional differences; however, trophoblast invasion is associated with proteolytic enzyme secretion, and this may release bound forms of VEGF, increasing their availability (Park et al., 1993).

Previously, in situ hybridization was used to localize the site of expression of mRNA encoding VEGF throughout pregnancy (Sharkey et al., 1993). On the fetal side, mRNA encoding VEGF was expressed in fetal macrophages within placental villi throughout gestation. In maternal decidua, VEGF expression was localized to glandular epithelium. However, the strongest site of expression was by maternal macrophages adjacent to the implantation site.

Two receptors for VEGF have been characterized, flt (fmslike tyrosine kinase) and KDR (kinase-insert-domain receptor) (De Vries et al., 1992; Terman et al., 1992); both are type three receptor tyrosine kinases. Until recently, these had been localized solely on vascular endothelial cells or their progenitors (Jakeman et al, 1992). These receptors have high affinity binding for VEGF, and play a crucial role in endothelial cell growth during both vasculogenesis and angiogenesis (Jakeman et al., 1992).

We have demonstrated that mRNA encoding flt is not solely confined to vascular endothelial cells but is present in human trophoblast, and flt expression at the implantation site is localized to invading extravillous trophoblast and to the 
trophoblastic shell surrounding the embryo (Charnock-Jones et al., 1994). This work indicates that extravillous trophoblast expressing mRNA encoding the VEGF receptor migrates towards the maternal decidua containing the VEGF expressing macrophages, and it is possible that these two cell types interact. The flk-1 receptor (the murine homologue of KDR) is also present in mouse trophoblast (Millauer et al., 1993).

These initial results suggest that at implantation, in addition to a role in angiogenesis, VEGF might act on novel target cells, extravillous trophoblasts, possibly by controlling their migration and differentiation in a similar way to endothelial cells. Having demonstrated the presence of VEGF and flt mRNA by in situ hybridization, we have now investigated the localization of VEGF and flt-like immunoreactivity throughout pregnancy.

\section{Materials and Methods}

\section{Tissue collection}

Tissue was collected from patients after informed consent, and the study was passed by the Ethical Committee of the Cambridge District Health Authority. First trimester tissue samples were collected from patients after termination of pregnancy (9-10 weeks), and term placentae and membranes from women undergoing elective Caesarean section for breech presentation. Three trophoblast samples from the first trimester and eight from term placentae were examined. Tissue was washed in sterile PBS and snap frozen in liquid nitrogen.

\section{Immunohistochemical staining}

Anti-VEGF and anti-flt purified polyclonal rabbit IgG antisera were purchased from Santa Cruz Biotechnology, Hatfield. The VEGF antibody was raised against a 20 amino acid synthetic peptide corresponding to residues 1-20, mapping at the amino terminus of VEGF. These amino acids are present in all the known VEGF splice variants. The flt antibody was raised against a peptide corresponding to amino acids $1312-1328$ at the carboxy terminus of flt. The specificity of the VEGF antiserum has been confirmed by Western blotting (Li et al., 1995).

Cryostat sections ( $10 \mu \mathrm{m}$ thick) were fixed in ice-cold acetone for $10 \mathrm{~min}$ and stored at $-70^{\circ} \mathrm{C}$ until required. Sections for staining were thawed and air-dried before further fixing in acetone for $2 \mathrm{~min}$. The sections were then rinsed in PBS. Endogenous peroxidase activity was destroyed by incubation for $10 \mathrm{~min}$ with 3\% hydrogen peroxide in PBS. For VEGF and flt, blocking was carried out with $10 \%(\mathrm{v} / \mathrm{v})$ goat serum in PBS. Sections were then incubated for $1 \mathrm{~h}$ with VEGF polyclonal rabbit antibody ( $\mathrm{I}: 300)$, or flt polyclonal rabbit antibody (1:300). Controls were VEGF antibody or flt antibody, preabsorbed overnight with a tenfold excess of VEGF (Santa Cruz Biotechnology) or ftt (Santa Cruz Biotechnology), respectively. As an additional control, sections were incubated with nonimmune rabbit IgG at the same concentration. Binding was visualized after incubation with a goat anti-rabbit biotinylated antibody (1:200) for $1 \mathrm{~h}$, and subsequent complexing with ABC (Vector Labs, Peterborough). The complex was detected with diaminobenzidine and hydrogen peroxide in
0.1 mol Tris- $-\mathrm{HCl} \mathrm{l}^{-1}(\mathrm{pH} 7.5)$. For the anti-cytokeratin and anti-CD68 mouse antibodies, blocking was carried out with $10 \%(\mathrm{v} / \mathrm{v})$ horse serum. Sections were then incubated with primary antibody, either anti-cytokeratin antibody (Dako, Copenhagen; 1:200) or anti-CD68 antibody (Dako; 1:50). These were detected with biotinylated rabbit anti-mouse (1:200) and subsequent $A B C$ peroxidase complexing. Sections were counterstained with haemalum and mounted in Depex (BDH, Poole).

\section{Extraction of Hofbauer cells from trophoblast villi}

Chorionic villi from first trimester placentae were separated from decidual tissue and washed in sterile Hanks balanced salts solution (HBSS) (Flow Laboratories, Irvine). Trophoblast cells were isolated as described, with some modifications by Loke and Burland (1988). Briefly, the villi were minced and incubated with $0.25 \%(\mathrm{w} / \mathrm{v}$ ) trypsin (Difco, Detroit, Michigan), $0.02 \%$ $(w / v)$ EDTA (Sigma, Poole) at $37^{\circ} \mathrm{C}$ for $10 \mathrm{~min}$, with constant stirring. The resulting suspension was filtered through muslin, and centrifuged at $400 \mathrm{~g}$ for $5 \mathrm{~min}$. The pellet was resuspended in HBSS and $10 \%(\mathrm{v} / \mathrm{v})$ newborn calf serum, and cultured in Labteck chamber slides for $1 \mathrm{~h}$ at room temperature (Nunc, Noperville, IL). After I h, non-adherent cells were removed. Attached cells were washed twice in PBS, and then fixed for immunocytohistochemistry in acetone for $10 \mathrm{~min}$. These cells were then stained for $\mathrm{flt}, \mathrm{CD} 68$ and cytokeratin as described previously.

\section{Double immunohistochemical staining of enriched Hofbauer cells}

Fluorescence double-staining for flt and the macrophage marker CD68 was performed on Hofbauer cells isolated as above. Slides were fixed in acetone for $10 \mathrm{~min}$ and then washed in PBS. They were then incubated for $I \mathrm{~h}$ in $50 \mu \mathrm{l}$ PBS containing a $1: 50$ dilution of flt polyclonal rabbit antibody and a 1:50 dilution of CD68 monoclonal mouse antibody. The slides were then washed in PBS and incubated for $\mathrm{Ih}$, in the dark, with a 1:200 dilution of both fluorescein isothiocyanate isomer 1 (FITC)-conjugated goat anti-mouse immunoglobulin (Dako) and tetramethylrhodamine isothiocyanate (TRITC) conjugated goat anti-rabbit immunoglobulin (Sigma Immuno Chemicals, St Louis, MO). Slides were washed in PBS and mounted in aqueous mounting medium and viewed immediately. Fading was prevented by keeping slides in the dark at $4^{\circ} \mathrm{C}$. As negative controls, the anti-flt antibody was preabsorbed overnight at $4^{\circ} \mathrm{C}$ with a tenfold excess of flt. In addition, slides were incubated with nonimmune rabbit $\operatorname{IgG}$ at the same concentration as the flt antiserum. These sections showed no detectable staining.

\section{Results}

Immunohistochemistry of vascular endothelial growth factor

First trimester. In first trimester villi, VEGF immunoreactivity was found primarily on scattered cells in the villous mesenchyme (labelled ' $h$ ' in Fig. Ic). Preabsorption with 

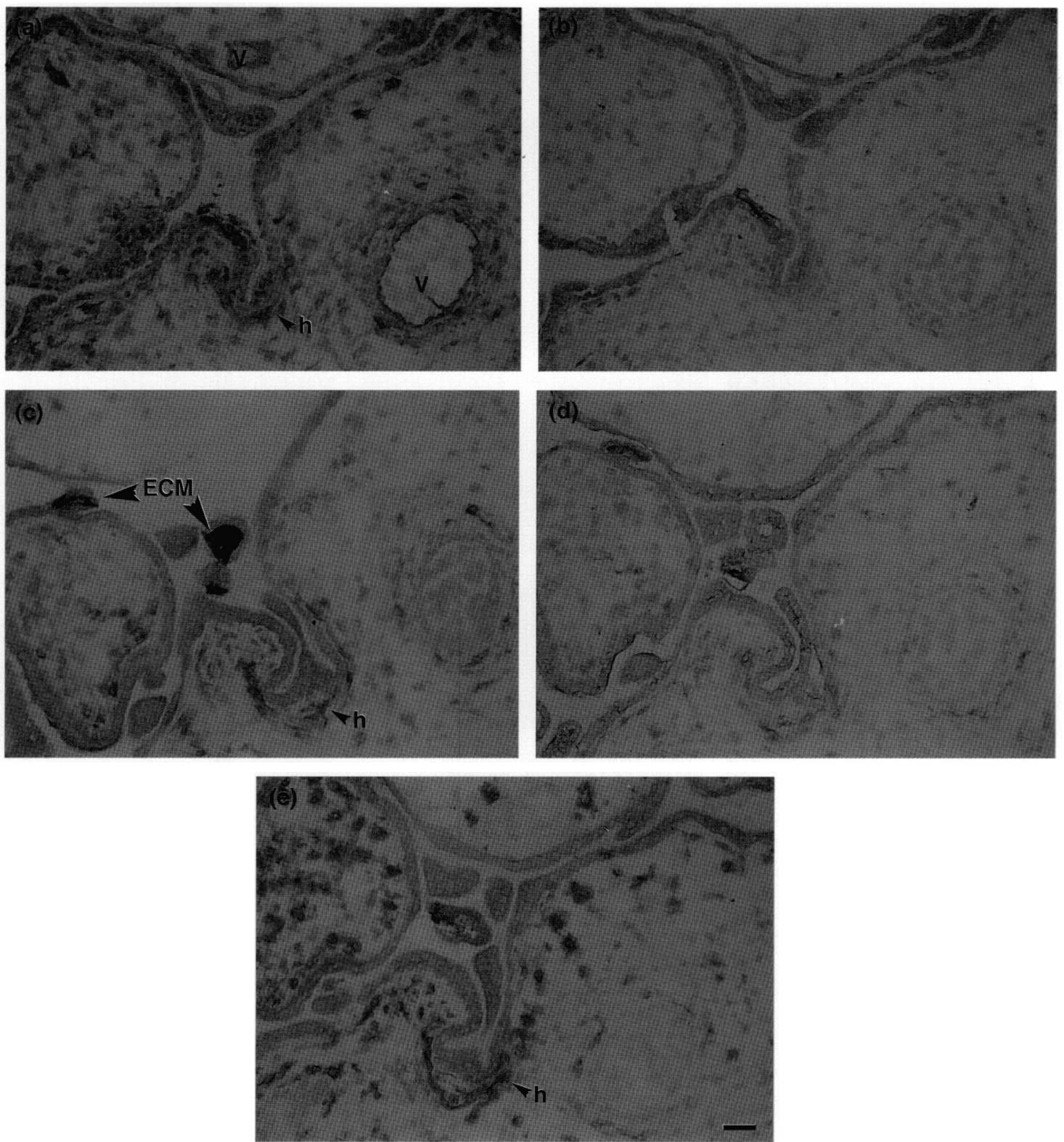

Fig. 1. Immunohistochemical detection of vascular endothelial growth factor (VEGF) and flt on serial frozen sections of first trimester trophoblast. (a) Placental villi stained with anti-flt antibody, showing positive staining on endothelial cells in fetal blood vessels $(v)$ and macrophages (h, fetal Hofbauer cells). (b) Control for (a), with anti-flt antibody preincubated with flt peptide before use. (c) Serial section from the same tissue stained with anti-VEGF antibody showing positive staining on extracellular matrix (ECM) and fetal Hofbauer cells. (d) Control for (c), with anti-VEGF antibody preincubated with VEGF peptide showing attenuation of VEGF immunoreactivity. (e) Serial section stained with anti-CD68 macrophage marker. Scale bar represents $50 \mu \mathrm{m}$.

peptide greatly reduced this staining (Fig. Id). Staining of serial sections with anti-CD68 antibody suggested that these VEGFpositive cells present within the villous mesenchyme had the same distribution as fetal macrophages and are likely to be Hofbauer cells. However, not all macrophages detected with CD68 showed detectable VEGF immunoreactivity (compare Fig. Ic with Fig. 1e). In addition, strong VEGF immunoreactivity was seen on fibrin-rich deposits of extracellular matrix (labelled 'ECM' in Fig. Ic). This also appeared specific, since it was greatly reduced by preincubation with peptide (Fig. Id).
In decidua, VEGF-like immunoreactivity was seen in glandular epithelium (labelled ' $g$ ' in Fig. 2a). Numerous isolated cells within the decidua also stained positively (Fig. 2a). This staining, together with the glandular immunoreactivity, was largely abolished by preincubation with peptide (Fig. 2b). Serial sections were stained with cytokeratin, which identifies extravillous trophoblast (EVT) in the decidua (Fig. 2c). The cells exhibiting strong VEGF immunoreactivity were not positive for cytokeratin, and could be distinguished morphologically from large granular lymphocytes (Bulmer and Sutherland, 

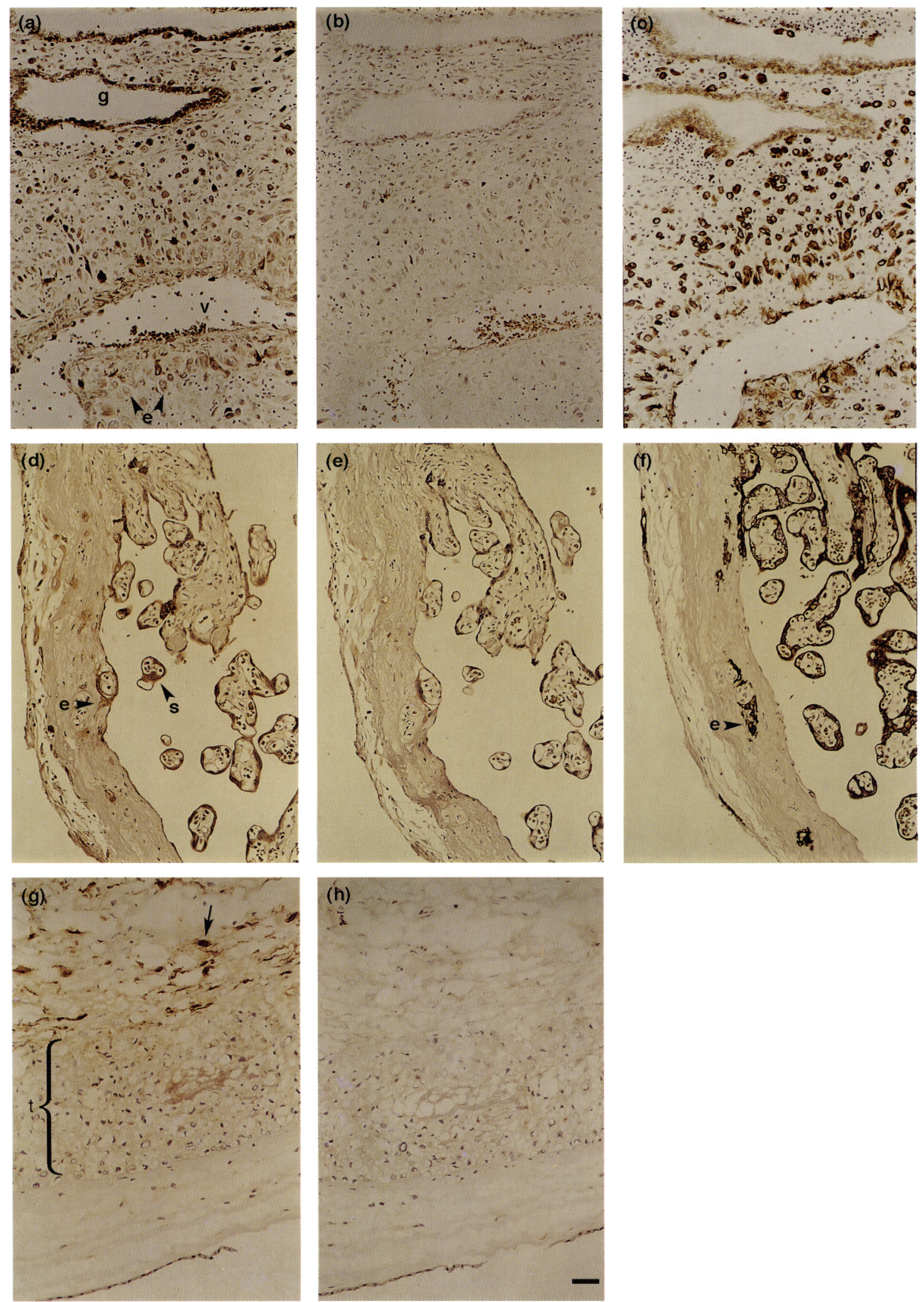
1984). For these reasons, together with the appearance of these cells, we suggest they are maternal macrophages. Extravillous trophoblast, identified both as cytokeratin-positive cells and by morphological criteria, showed only weak VEGF immunoreactivity (labelled ' $e$ ' in Fig. $2 \mathrm{a}$ ).

Term placenta. In term placenta from elective Caesarean section, VEGF-like immunoreactivity was demonstrated in the syncytiotrophoblast surrounding some villi (labelled ' $s$ ' in Fig. 2d). Isolated extravillous trophoblast in the maternal decidual bed also stained positively for VEGF (labelled ' $e$ ' in Fig. 2d), an effect abolished by preincubation with peptide (Fig. 2e). Immunohistochemical localization of cytokeratin in semi-serial sections confirmed their identity (Fig. 2f). In addition, Hofbauer cells within the villous mesenchyme showed VEGF-like immunoreactivity, as did some areas of extracellular matrix as seen in the first trimester (data not shown).

The amnion and chorion were also analysed. The amnion did not show any obvious VEGF-like immunoreactivity. However, expression did occur in scattered cells in the fibrous layer of connective tissue (Fig. 2g,h). The tissue distribution of these cells closely matched that of cells stained positively for the macrophage marker CDI4 (data not shown). There was no VEGF immunoreactivity in the chorionic trophoblast cell layer, labelled ' $t$ ' in Fig. $2 \mathrm{~g}$.

\section{Immunohistochemistry of flt}

First trimester. In trophoblast, immunoreactive flt was found on fetal endothelial cells lining blood vessels in the villi (labelled ' $v$ ' in Fig. 1a). This immunoreactivity was abolished by preincubation with peptide (Fig. Ib). In addition, cells in the villous mesenchyme showed flt immunoreactivity (labelled ' $h$ ' in Fig. 1a). These cells had a similar distribution to the VEGF-expressing cells, and CD68-positive macrophages (compare Figs Ia,c and e).

Term placenta. In term placenta, immunoreactive flt was again demonstrated in fetal endothelial cells (Fig. 3c). As in first trimester trophoblast, there was consistent staining of cells in the villous mesenchyme, which appeared to be fetal villous macrophages (labelled ' $h$ ' in Fig. 3c). Immunostaining of macrophages must be interpreted with caution, since nonspecific binding of $\operatorname{IgG}$ to $\mathrm{Fc}$ receptors can give rise to false positives. However, the apparent immunoreactivity was reduced markedly by pre-absorption with peptide before staining (Fig. 3d). In addition, incubation of tissue sections with purified rabbit $\operatorname{lgG}$ at the same concentration produced similar staining to that in Fig. $3 \mathrm{~d}$ (data not shown).
Extravillous trophoblast in the maternal decidual bed also stained strongly (labelled ' $\mathrm{e}$ ' in Fig. 3e). Some staining of villous syncytiotrophoblast was also seen at term (labelled 's' in Fig. 3e), but this was patchy with some villi apparently weak or negative. These cells were enriched from first trimester trophoblast, and double-stained with antibodies to flt and CD68 to confirm that Hofbauer cells stained for flt (Fig. 4). These cells stained both for flt and CD68, confirming that they are Hofbauer cells. Anti-cytokeratin immunoreactivity was minimal, indicating that a relatively pure population of macrophages had been obtained.

The results are summarized in Table 1 .

\section{Discussion}

This study demonstrates the presence of VEGF and flt immunoreactivity in human decidua and trophoblast in first trimester and term placenta. Both mRNA encoding VEGF and VEGF immunoreactivity in first trimester trophoblast were localized to Hofbauer cells within the villous mesenchyme and, in the decidua, to glandular epithelium and maternal macrophages. In a previous study, we showed that mRNA encoding VEGF was expressed by villous trophoblast at low concentrations in first trimester with increased expression towards term (Sharkey et al., 1993). No VEGF immunoreactivity was detected in first trimester trophoblast but by term, VEGF staining was present (Fig. $2 \mathrm{~d}$ ). However, this was patchy and localized primarily to the surface facing the maternal circulation. Apart from this cell type, the present study has confirmed that those cells expressing mRNA encoding VEGF do indeed show VEGF immunoreactivity.

There have been two other reports of VEGF expression in the human placenta. VEGF mRNA isoforms were detected by RT-PCR in placental fibroblasts cultured in vitro (Anthony et al., 1994). This study did not address whether these fibroblasts express VEGF in vivo. The second study, using a monoclonal antibody to VEGF, reported VEGF immunolocalization only in villous cytotrophoblast in first trimester and in syncytiotrophoblast thereafter (Jackson et al., 1994). In this study, we found no cytotrophoblast staining, and additional VEGF immunolocalization in Hofbauer cells. The differences in the results may be due to antisera of different specificities, or different staining protocols.

Immunoreactive VEGF was also localized to some areas of extracellular material. This was markedly reduced by preincubation of the antibody with peptide, and is likely to represent heparin-bound isoforms of VEGF attached to this matrix. The five different VEGF splice variants differ in their binding to

Fig. 2. Immunohistochemical detection of vascular endothelial growth factor (VEGF) on serial frozen sections of decidua, amnion and chorion, and placenta. (a) First trimester decidua stained with anti-VEGF antibody. Positive immunoreactivity is noted on glandular epithelium (g), and isolated cells, which are likely to be macrophages. e, extravillous trophoblast; v, fetal blood vessels. (b) Control for (a), showing anti-VEGF antibody preincubated with peptide before use. (c) Serial section showing staining with anti-cytokeratin antibody, indicating that the positively staining decidual cells in (a) are not trophoblasts. (d) Term placenta stained with anti-VEGF antibody showing positive immunoreactivity on syncytiotrophoblast (s) and isolated extravillous trophoblast, e. (e) and (f) are serial sections stained with anti-VEGF antibody preabsorbed with peptide before use and anti-cytokeratin, respectively. (g) Amnion and chorion stained with anti-VEGF antibody, showing positively staining cells in the chorion only (arrow), corresponding to sites of macrophage expression. There is no significant staining of the chorionic trophoblast ( $t$ ). (h) Control of a serial section stained with anti-VEGF antibody preabsorbed with peptide before use. Scale bar represents $40 \mu \mathrm{m}$. 

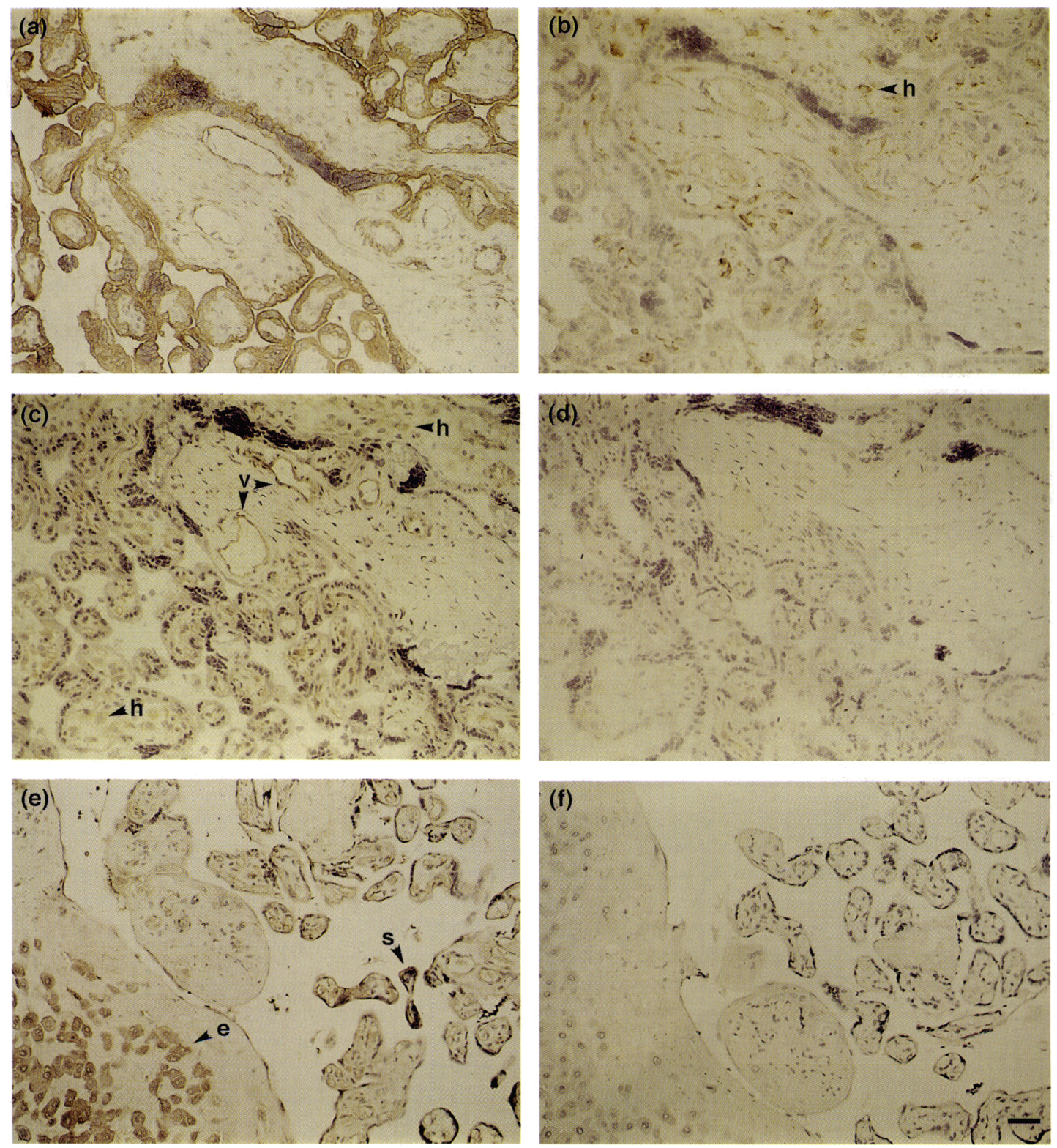

Fig. 3. Immunohistochemical detection of flt in term placenta. (a) Section of placenta stained with anti-cytokeratin, showing trophoblast. (b) Section stained with anti-CD68 showing macrophages (Hofbauer cells, h). (c) Serial section stained with anti-flt antibody, showing flt immunoreactivity on fetal endothelial cells lining blood vessels (v). In addition, cells stained positively in the villous mesenchyme appear to be Hofbauer cells. (d) Control for (c), with anti-flt antibody preincubated with flt peptide. (e) Section from decidua stained with anti-flt antibody, showing immunoreactivity on extravillous trophoblast (e) and patchy staining of syncytiotrophoblast (s). (f) Control for (e) with anti-flt antibody preincubated with flt peptide. Scale bar represents $50 \mu \mathrm{m}$.

heparin. VEGF ${ }_{121}$ is secreted and freely soluble, $V_{E G F} 165$ is secreted but $50-70 \%$ binds to components on the cell surface (Houck et al., 1992). VEGF ${ }_{189}, V$ EGF $_{206}$ and probably VEGF ${ }_{145}$ are highly basic proteins, tightly bound to the extracellular matrix (ECM), and released by heparinase, indicating that the binding site involves heparin-binding proteoglycans (Park et al., 1993).

The VEGF immunoreactivity in the ECM detected in this study indicates that some of the isoforms of VEGF are bound to the ECM in vivo. This may therefore provide a reservoir of biologically active VEGF, available to endothelial cells or trophoblast after its release (Park et al., 1993). This mechanism may be important during implantation as many proteases, not just heparinase, can release active VEGF from the ECM (Houck et al., 1992) and these proteases are essential for trophoblast invasion (Strickland and Richards, 1992). Park et al. (1993) reported that, even whilst bound to the ECM, VEGF 189 and $\mathrm{VEGF}_{206}$ are bioactive. There is also a growing body of evidence indicating that other growth factors are stored in the ECM and are released with its degradation as bioactive forms, 

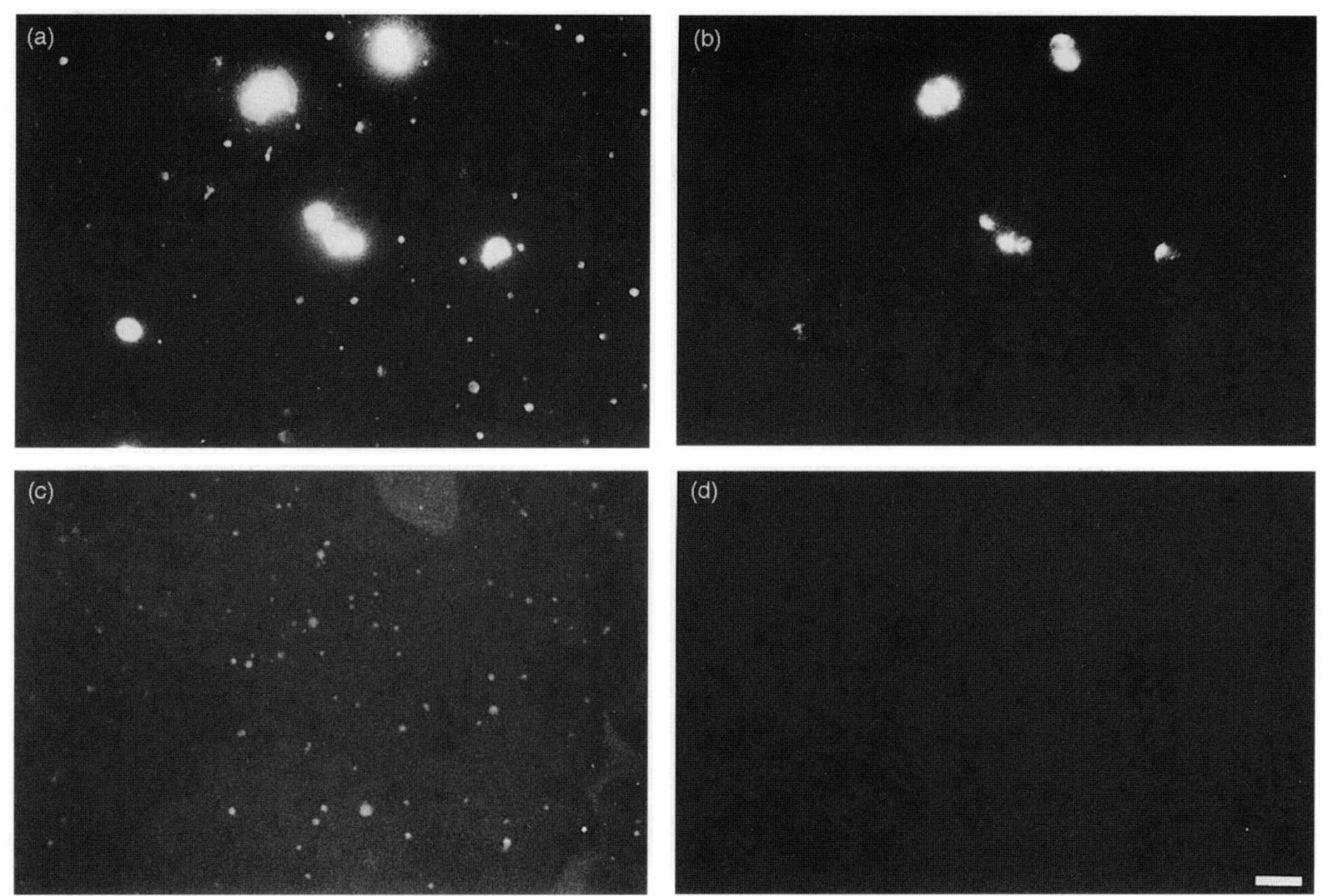

Fig. 4. Double staining of enriched Hofbauer cells. (a) Fluorescent staining of Hofbauer cells with anti-flt antibody. (b) The same cells as (a), with fluorescent staining for anti-CD68. (c) Enriched Hofbauer cells stained as in (a), but with non-immune rabbit lgC at the same concentration as the anti-fit antibody. (d) Enriched Hofbauer cells stained as in (b), but with an irrelevant isotype matched primary antibody. Scale bar represents $10 \mu \mathrm{m}$

Table 1. Summary of immunolocalization of vascular endothelial growth factor (VEGF) and flt in decidua and placenta

\begin{tabular}{ll}
\hline Ist Trimester & \multicolumn{1}{c}{ Term } \\
\hline VEGF & \\
Hofbauer cells & Hofbater colls \\
Extracelluiar matrix & Extracellular matrix \\
Decidual glandular epithelium & Extravillous trophoblast \\
Decidual macrophages & \\
HIt & \\
Endothelial cells & Endothelial colls \\
Hofbauer cells & Hofbauer cells \\
Extravillous trophoblast & Extravillous trophoblast \\
\hline
\end{tabular}

these include, leukaemia inhibitory factor (Rathjen it al., 1990). platelet derived growth factor (Raines and Ross, 1992) and fibroblast growth factor (Vlodavsky $t$ t il., 1987; Saksela and Rifkin, 1990).

Thus far, two receptors for VEGF have been identified: flt and KDR (De Vries et al., 1992; Terman of al, 1992). Using in situ hybridization, we have demonstrated that the cytotrophoblast shel and EVT migrating into the decidua express mRNA encoding fit strongly (Charnock-Jones if al., 1994). In the present study, flt immunoreactivity was detected on EVT. particularly at term. However, there was only weak staining of villous trophoblast at term. An additional site of flt immunoreactivity was Hotbauer cells in placental villi, which expressed Alt throughout pregnancy. We were concerned to exclude the possibility that this was due to spurious immunostaining of macrophages owing to interactions between Fc receptors and $\lg \mathrm{G}$, which is a common problem. However, two facts suggest that, in this case, the Hofbauer cells do show flt immunoreactivity. First, the immunostaining was abolished by preincubation of the antiscrum (with excess peptide) to which it was raised. Second, a purified population of placental macrophages stained for flt, confirming the identity of the colls expressing flt immunoreactivity (Fig. +).

The expression pattern of VEGF and flt immunoreactivity suggests that VEGF may be involved in both angiogenesis and EVT migration and differentiation. It is known that VEGF is a potent endothelial cell mitogen (Ferrara and Henzel, 1989) and mediator of vascular permeability (Leung of inl, 1989). Within the villi, VEGF expression by macrophages could control endothelial cell growth and hence capilary formation. The endothelial cells show flt immunoreactivity throughout pregnancy. The VEGF expression persists until term, when the primary role may be in controlling vessel permeability.

In addition to angiogenesis, VEGF and flt may be involved in controlling the invasion of EVT into the maternal decidua. As EVT invades, it differentiates into either interstitial 
trophoblast or endovascular trophoblast. The latter invades the maternal spiral arteries, converting them into large diameter vessels capable of maintaining the growing fetus and placenta. We have now demonstrated fit immunoreactivity on migrating EVT in the decidua. VEGF induces proliferation in endothelial cells and is chemotactic for human umbilical vein endothelial cells (Koch et al., 1994). It seems likely that VEGF/flt interactions may also affect the proliferation and migration of extravillous trophoblast, which expresses flt and moves to decidua, a region of high VEGF expression. Studies carried out in vitro in this laboratory provide some support for this idea. The trophoblast-like choriocarcinoma cell line, BeWo, expresses mRNA encoding flt. We have shown that addition of recombinant VEGF to this line increases $\left[{ }^{3} \mathrm{H}\right]$ thymidine uptake in a manner similar to that of VEGF in endothelial cells. This effect was blocked by neutralizing antibody (Charnock-Jones et al., 1994), indicating that proliferation of extravillous trophoblast may be an effect of VEGF-flt interaction. This is possible for the proliferating extravillous trophoblast at the base of the trophoblast columns; however, extravillous trophoblast in decidua is nonproliferating and therefore other actions such as control of migration and differentiation may be important. In term placenta, the EVT continues to express flt but now also expresses VEGF, indicating a shift from a paracrine to autocrine mode of action for VEGF. It is not clear what effect VEGF has on the sessile placental giant cells.

A novel finding in this study is the expression of flt by Hofbauer cells throughout pregnancy. VEGF has been shown to be chemotactic for blood monocytes (Clauss et al., 1990), indicating that these cells can express VEGF receptors. Therefore, in addition to potential regulation of endothelial cell function in the villi, VEGF made by Hofbauer cells may also act by an autocrine mechanism.

In summary, we have localized both VEGF and flt immunoreactivity in decidua and placenta. These results, together with our data on localization of mRNA encoding VEGF (Sharkey et al., 1993), suggest that VEGF may act on three cell types in the placenta. In the villi, VEGF made by Hofbauer cells could act on endothelial cells controlling capillary formation and permeability throughout gestation. Hofbauer cells also express the VEGF receptor, flt, allowing autocrine regulation of their function. EVT expressing flt migrates through maternal decidua exhibiting a high amount of VEGF expression by glandular epithelium, and maternal macrophages. This is the first localization of flt immunoreactivity to cells other than endothelial cells, and confirms the results of Charnock-Jones et al. (1994). Therefore, this growth factor may be involved in the control of EVT migration and, later in pregnancy, the function of differentiated EVT, which continue to express flt until term.

Along with other growth factors, the VEGFs are likely to be involved in the complex interactions between steroids, growth factors, proteases and extracellular matrix that regulate angiogenesis in the placenta and trophoblast invasion. Disturbance of the normal sequence of migration and differentiation of trophoblast may lead to serious disorders of both fetus and mother, such as pre-eclampsia and intrauterine growth retardation (Fisher and Damsky, 1993). Defining the mechanisms controlling trophoblast migration, growth, and differentiation is important in understanding these conditions.
The authors thank the Research and Development Department of the Anglia and Oxford Regional Health Authority who funded this project. The authors also thank the Consultant, theatre and Pathology staff of Addenbrooke's Hospital, Cambridge for their help with this study. J. Cooper was supported by a research fellowship from the AORHA. M. Sharkey was supported by MRC project grant G8909970SB, D. S. Charnock-Jones was supported by MRC project grant G8928836SB. J. McLaren was supported by the Wellcome Trust project grant no. 037011/Z/92/Z.

\section{References}

Anthony FW, Wheeler T, Elcock CL, Pickett M and Thomas EJ (1994) Short report: identification of a specific pattern of vascular endothelial growth factor mRNA expression in human placenta and cultured placental fibroblasts Placenta 15 557-561

Bulmer JN and Sutherland CA (1984) Immunohistological characterisation of lymphoid cell populations in the early human placental bed Immunology $\mathbf{5 2}$ $349-357$

Charnock-Jones DS, Sharkey AM, Rajput-Williams J, Burch D, Schofield JP, Fountain SA, Boocock CA and Smith SK (1993) Identification and localisation of alternatively spliced mRNAs for vascular endothelial growth factor in human uterus and estrogen regulation in endometrial carcinoma cell lines Biology of Reproduction 48 1120-1128

Charnock-Jones DS, Sharkey AM, Boocock CA, Ahmed A, Pelvin R, Ferrara N and Smith SK (1994) Vascular endothelial growth factor-receptor localisation and activation in human trophoblast and choriocarcinoma cells Biology of Reproduction 51 524-530

Clauss M, Gerlach M, Gerlach H, Brett J, Wang F, Familletti PC, Pan Y-CE, Olander JV, Connolly DT and Stern D (1990) Vascular permeability factor: a tumourderived peptide that induces endothelial cell and monocyte procoagulant activity, and promotes monocyte migration Journal of Experimental Medicine $172 \quad 1532-1545$

De Vries C, Escobedo JA, Ueno H, Houck K, Ferrara N and Williams LT (1992) The fms-like tyrosine kinase, a receptor for vascular endothelial growth factor Science 255 989-991

Ferrara N (1993) Vascular endothelial growth factor Trends in Cardiovascular Medicine 3 244-250

Ferrara N and Henzel WJ (1989) Pituitary follicular cells secrete a novel heparin-binding growth factor specific for vascular endothelial cells Biochemical and Biophysical Research Communications 161 851-858

Findlay JK (1986) Angiogenesis in reproductive tissues Journal of Endocrinology $111357-366$

Fisher SJ and Damsky CH (1993) Human cytotrophoblast invasion Seminars in Cell Biology 4 183-188

Houck KA, Leung DW, Rowland AM, Winer J and Ferrara N (1992) Dual regulation of vascular endothelial growth factor bioavailability by genetic and proteolytic mechanisms Journal of Biological Chemistry $26726031-$ 26037

Jackson MR, Carney EW, Lye SJ and Knox Ritchie JW (1994) Localisation of two angiogenic growth factors (PDECGF and VEGF) in human placentae throughout gestation Placenta 15 341-353

Jakeman LB, Winer J, Bennett GL, Altar CA and Ferrara N (1992) Binding sites for vascular endothelial growth factor are localised on endothelial cells in adult rat tissues Journal of Clinical Investigation $89244-253$

Klagsbrun M and D'Amore PA (1991) Regulators of angiogenesis Annual Review of Physiology 53 217-239

Koch AE, Harlow LA, Haines GK, Amento EP, Unemori EN, Wong WL, Pope RM \& Ferrara N (1994) Vascular endothelial growth factor. A cytokine modulating endothelial function in rheumatoid arthritis Journal of Immunology $\mathbf{1 5 2}$ 4149-4156

Leung DW, Cachianes G, Kuang W-J, Goeddel DV and Ferrara N (1989) Vascular endothelial growth factor is a secreted angiogenic mitogen Science $\mathbf{2 4 6}$ 1306-1309

Li J, Perrella MA, Tsai J-C, Yet S-F, Hsieh C-M, Yoshizumi M, Patterson C, Endege WO, Zhou F and Lee M-E (1995) Induction of vascular endothelial growth factor gene expression by interleukin-IB in rat aortic smooth muscle cells Journal of Biological Chemistry 270 308-312

Loke YW and Burland K (1988) Human trophoblast cells cultured in modified medium and supported by extracellular matrix Placenta 9 173-182 
Mignatti P, Tsuboi R, Robbins E and Rifkin DB (1989) In vitro angiogenesis on the human amniotic membrane: requirement for basic fibroblast growth factor-induced proteinases Journal of Cell Biology 108 671-682

Millauer B, Wizigman-Voos S, Schnurch H, Martinez R, Moller NPH, Risau W and Ullrich A (1993) High affinity VEGF binding and developmental expression suggest Flk-1 as a major regulator of vasculogenesis and angiogenesis $\mathrm{Cell}$ $72835-846$

Park JE, Keller G-A and Ferrara N (1993) The vascular endothelial growth factor (VEGF) isoforms: differential deposition into the subepithelial extracellular matrix and bioactivity of extracellular matrix-bond VEGF Molecular Biology of the Cell 4 1317-1326

Raines EW and Ross R (1992) Compartmentalization of PDGF on extracellular binding sites dependent of exon-6-encoded sequences Journal of Cell Biology $116533-543$

Saksela O and Rifkin DB (1990) Release of basic fibroblast growth factorheparin sulfate complexes from endothelial cells by plasminogen activatormediated proteolytic activity Journal of Cell Biology 110 767-775
Sharkey AM, Charnock-Jones DS, Boocock CA, Brown KD and Smith SK (1993) Expression of messenger RNA for vascular endothelial growth factor in human placenta Journal of Reproduction and Fertility $99609-615$

Strickland S and Richards WG (1992) Invasion of the trophoblasts Cell 71 355-357

Terman BI, Dougher-Vermazen M, Carrion ME, Dimitrov D, Armellino DC, Gospodarowicz D and Bohlen P (1992) Identification of the KDR tyrosine kinase as a receptor for vascular endothelial cell growth factor Biochemical and Biophysical Research Communications 187 1579-1586

Unemori EN, Ferrara N, Bauer EA and Amento EP (1992) Vascular endothelial growth factor induces interstitial collagenase expression in human endothelial cells Journal of Cellular Physiology 153 557-562

Vlodavsky I, Folkman J, Sullivan R, Fridman R, Ishai-Michaeli R, Sasse J and Klagsbrun MN (1987) Endothelial cell derived basic fibroblast growth factor synthesis and deposition into subendothelial extracellular matrix Proceedings National Academy of Sciences USA 84 2292-2296 